\title{
EL BIEN JURÍDICO PROTEGIDO EN LOS DELITOS CONCURSALES
}

[The object of legal protection in bankruptcy crimes]

\author{
Laura MAYER LuX* \\ Pontificia Universidad Católica de Valparaíso
}

\begin{abstract}
RESUMEN
El presente trabajo tiene por objeto definir el bien jurídico tutelado por los delitos concursales incorporados al Código Penal chileno a través de la Ley $N^{\circ} 20.720$ de 2014. Con dicha finalidad, el análisis comienza con una revisión crítica de las principales tesis que se han propuesto en esta materia. El estudio culmina con una toma de posición, basada fundamentalmente en la nueva regulación positiva de este grupo de ilícitos.

\section{Palabras Clave}

Intereses patrimoniales - orden público económico - delitos económicos - procedimientos concursales insolvencia.
\end{abstract}

ABSTRACT

AвSTRACT
This paper aims to define the object
of legal protection in bankruptcy crimes
incorporated into the Chilean Penal
Code through Law No. 20,720 in 2014 .
With this purpose, the analysis begins
with a critical review of the main theses
proposed in this matter. The study
culminates with the adoption of a stance,
based fundamentally on the new positive
regulation of this group of illicit.
KEY words
Property interests - economic public
order - economic crimes - bankruptcy
proceedings - insolvency.

RECIBIDO el 30 de abril y ACEPTADO el 7 de noviembre de 2017

* Profesora de derecho penal en la Pontificia Universidad Católica de Valparaíso. Dirección postal: Brasil 2950, Valparaíso, Chile. Correo electrónico: laura.mayer@pucv.cl. Agradezco las valiosas sugerencias de Paula López Baquedano, Nadín Vargas Sielfeld y Jaime Vera Vega. 


\section{Presupuestos de los Que Se parte y estado general de LA CUESTIÓN}

Como es sabido, el bien jurídico cumple diversas funciones de gran relevancia para el Derecho penal. Así, la afectación de un bien jurídico sirve de fundamento a la pena de los comportamientos que lo lesionan o ponen en peligro ${ }^{1}$ y constituye un presupuesto insoslayable para el ejercicio del ius puniendi estatal ${ }^{2}$. Además, la importancia relativa de un bien jurídico y su nivel de afectación (lesión o peligro) operan como criterio para el establecimiento de penas proporcionales ${ }^{3}$. El bien jurídico permite igualmente identificar el injusto específico de cada delito ${ }^{4}$ (lo que puede tener consecuencias, por ejemplo, en materia de concurso aparente de leyes penales $^{5}$ ), así como sistematizar los delitos que integran la Parte Especial ${ }^{6}$ y orientar la interpretación de las distintas conductas que ellos castigan? De ahí la importancia de establecer cuál es el bien jurídico tutelado por un determinado delito o grupo de delitos.

Tanto el concepto de "bien jurídico" como el sentido y alcance de su protección punitiva han sido objeto de muchísimas investigaciones, cuyo análisis detallado no puede abordarse en el presente trabajo. En conside-

${ }^{1}$ KaHLO, Michael, Über den Zusammenhang von Rechtsgutsbegriff und objektiver Zurechnung im Strafrecht, en HefEndeHL, Roland - vON Hirsch, Andrew - Wohlers, Wolfgang (editores), Die Rechtsgutstheorie (BadenBaden, Nomos, 2003), p. 26.

${ }^{2}$ Ferrajoli, Luigi, El principio de lesividad como garantía penal (traducción de Diana Restrepo Rodríguez), en Revista de Derecho Penaly Criminología 8 (2012), p. 7; MiR PUIG, Santiago, Bien jurídico y bien jurídicopenal como límites del Ius puniendi, en Estudios Penales y Criminológicos 14 (1989-1990), pp. 205 y ss.

${ }^{3}$ Hassemer, Winfried, Darf es Straftaten geben, die ein strafrechtliches Rechtsgut nicht in Mitleidenschaft qiehen?, en HefendeHL, Roland - vON Hirsch, Andrew - Wohlers, Wolfgang (editores), Die Rechtsgutstheorie (BadenBaden, Nomos, 2003), p. 60.

${ }^{4}$ Bustos, Juan, Política criminal y bien jurídico en el delito de quiebra, en Anuario de derecho penal y ciencias penales 43 (1990), p. 33.

${ }^{5}$ Véase Lascurain, Juan Antonio, Bien jurídico y legitimidad de la intervención penal, en Revista Chilena de Derecho 22 (1995) 2, pp. 260 y s.

${ }^{6}$ Fernández, Gonzalo, Bien jurídico y sistema del delito (Montevideo - Buenos Aires, B de f, 2004), pp. 149 y s.

${ }^{7}$ Romano, Mario, Zur Legitimation der Strafgesetze. Zu Fähigkeit und Grenzen der Rechtsgutstheorie, en HeInrich, Manfred - Jäger, Christian - Schünemann, Bernd (editores), Strafrecht als Scientia Universalis, Festschrift für Claus Roxin zum 80. Geburtstag am 15. Mai 2011 (Berlin - New York, De Gruyter, 2011), I, p. 166. Respecto de los delitos vinculados con la insolvencia Dannecker, Gerhard - KNIERIM, Thomas HagemeIer, Andrea, Insolvenzstrafrecht (2. ${ }^{a}$ edición revisada, Heidelberg, C. F. Müller, 2012), p. 19, p. 26. 
ración a las finalidades que aquí se persiguen, se asumirá que los bienes jurídicos son aquellas condiciones materiales e inmateriales de las personas, cosas o instituciones, que sirven al libre desarrollo de la persona en un Estado democrático de derecho ${ }^{8}$. Asimismo, el trabajo partirá de la base de que para cumplir apropiadamente las funciones que les son propias, los bienes jurídicos deben identificarse directa o indirectamente con intereses concretos $^{9}$ de personas concretas, cuya tutela punitiva se justifica en caso de ataques graves ${ }^{10}$ de terceros, a la vez que sólo resulta legítima si logra compatibilizarse con las normas constitucionales que nos rigen ${ }^{11-12}$.

Los nuevos delitos concursales que puede cometer (quien actúe por) la empresa deudora, o bien, el veedor o liquidador de bienes, suponen un procedimiento concursal, ya sea de reorganización o de liquidación. En términos generales, dichos procedimientos, actualmente regulados en la Ley N. ${ }^{\circ} 20.720$, constituyen mecanismos de tutela o defensa colectiva de los acreedores ante la insolvencia de la empresa deudora. Por su parte, la insolvencia "es un estado patrimonial vicioso y complejo que se traduce en un desequilibrio entre su activo liquidable y su pasivo exigible, de modo tal que coloca a su titular en la incapacidad objetiva de cumplir, actual o potencialmente, los compromisos que lo afectan"13.

Los delitos concursales incorporados por la Ley N. ${ }^{\circ} 20.720$ se consagran junto a las defraudaciones, concepto que se extiende, ciertamente, a las defraudaciones contempladas en el Párrafo $7^{\circ}$ del Título IX del Libro II CP., pero que también puede referirse a aquellas reguladas en el Párrafo $8^{\circ}$ del mismo Título y Libro. Pues bien, los delitos concursales

${ }^{8}$ Mayer Lux, Laura - Vera Vega, Jaime, Relevancia jurídicopenal de la conducción vehicular sin la correspondiente licencia, en Doctrina y Jurisprudencia Penal, Edición Especial (2014), pp. 119 y s.

9 SternbergLieben, Detlev, Rechtsgut, Verbältnismäßigkeit und die Freiheit des Strafgesetzgebers, en HeFEndeHL, Roland - vON Hirsch, Andrew - WoHLERs, Wolfgang (editores), Die Rechtsgutstheorie (BadenBaden, Nomos, 2003), p. 72.

${ }^{10}$ Corcoy, Mirentxu, Delitos de peligro y protección de bienes jurídicopenales supraindividuales (Valencia, Tirant lo Blanch, 1999), pp. 194 y s.; Muñoz Conde, Francisco, Introducción al derecho penal (2. edición, Montevideo - Buenos Aires, B de f, 2001), pp. 106 y s., p. 124.

${ }^{11}$ Frister, Helmut, Strafrecht Allgemeiner Teil (7. a edición, München, Beck, 2015), p. 40; Rudolphi, HansJoachim - JäGer, Christian, Vor $\int 1$, en Wolter, Jürgen (editor), Systematischer Kommentar zum Strafgesetzbuch, SS 145 b StGB (8a edición, Köln, Carl Heymanns Verlag, 2014), I, nm. 13.

${ }^{12}$ Una reflexión análoga a la que aquí precede puede verse en MAYER Lux, Laura, El bien jurídico protegido en los delitos informáticos, en Revista Chilena de Derecho, 44 (2017) 1.

${ }_{13}$ Puga, Juan Esteban, Derecho Concursal, Del procedimiento concursal de liquidación, Ley $N^{\circ} 20.720$ (reimpresión de la 4. ${ }^{a}$ edición actualizada, Santiago, Editorial Jurídica de Chile, 2015), p. 78. 
pueden ser entendidos como figuras delictivas que, al igual que las defraudaciones, se valen de un medio fraudulento para perjudicar los intereses patrimoniales de otros, en este caso, de los acreedores. En el fondo, de acuerdo con este razonamiento, no es posible efectuar una distinción tajante entre delitos concursales y defraudaciones ${ }^{14-15}$, pues tanto a los primeros como a las segundas subyace, en algún sentido, la realización de un comportamiento tendiente al perjuicio patrimonial de otro, a través de determinados medios ${ }^{16}$.

En materia de delitos concursales y, más ampliamente, de delitos relacionados con el concepto de insolvencia ${ }^{17}$, existen dos grandes grupos de planteamientos relativos al bien jurídico tutelado: las tesis "patrimonialistas" y las tesis "metapatrimonialistas"18. Las primeras entienden que los delitos concursales protegen un bien jurídico individual (o sea, un interés que es de titularidad o sirve a una persona determinada o a un grupo de personas determinadas ${ }^{19}$ ); las segundas, por el contrario, consideran que los delitos concursales tutelan un bien jurídico colectivo o supraindividual (o

${ }^{14}$ En esa línea, a propósito de los delitos regulados en la antigua Ley de Quiebras, Etcheberry, Alfredo, Derecho Penal, Parte Especial (reimpresión de la 3. ${ }^{a}$ edición revisada y actualizada, Santiago, Editorial Jurídica de Chile, 2010), III, p. 380. De otra opinión, Garrido Montt, Mario, Derecho Penal, Parte Especial (reimpresión de la 4. ${ }^{a}$ edición, Santiago, Editorial Jurídica de Chile, 2011), IV, p. 309.

${ }^{15}$ No debe perderse de vista que, en el texto original del CP., los delitos concursales se encontraban regulados en el Párrafo $7^{\circ}$ del Título IX del Libro II, denominado De las defraudaciones. La Ley N. ${ }^{\circ} 4.558$, de 4 de febrero de 1929, conocida como Ley de Quiebras, eliminó del CP. las defraudaciones del deudor dedicado al comercio, mientras que las defraudaciones del deudor no comerciante permanecieron en dicho cuerpo normativo. Por su parte, la Ley N. ${ }^{\circ} 20.720$, de 9 de enero de 2014, sobre Reorganización y Liquidación de Empresas y Personas, introdujo importantes modificaciones al Párrafo $7^{\circ}$, al que devolvió toda la regulación de los comportamientos delictivos vinculados con la insolvencia, y que pasó a llamar De los delitos concursales y de las defraudaciones.

${ }^{16}$ Ello es bastante claro tratándose del delito del artículo 463 CP., que expresamente exige que el deudor ejecute actos o contratos que disminuyan su activo o aumenten su pasivo sin otra justificación económica o jurídica que la de perjudicar a sus acreedores; pero también puede afirmarse respecto de los restantes delitos concursales, todos los cuales giran en torno a la idea de menoscab ar las posibilidades de los acreedores de perseguir sus créditos en el patrimonio del deudor.

${ }^{17}$ Concepto en el que pueden incluirse los delitos concursales (artículos 463 a 465 bis CP.), el alzamiento de bienes e incluso el otorgamiento de contratos simulados en perjuicio de los acreedores (artículo 466 CP.).

${ }^{18}$ Véase Caballero, Felipe, Insolvencias punibles (Madrid, Iustel, 2008), pp. 64 y ss., pp. 104 y ss.

${ }^{19}$ KINDHÄUSER, Urs, Gefäbrdung als Straftat (Frankfurt am Main, Vittorio Klostermann, 1989), p. 144. 
sea, un interés que es de titularidad o sirve a la generalidad de las personas que integran el cuerpo social $\left.{ }^{20}\right)$. De ahí que un sector de la doctrina aluda, de forma más genérica, a tesis "individualistas" y a tesis "colectivas" 21 . A estos planteamientos suele añadirse una tercera propuesta, que puede calificarse de mixta, pues mezcla la tesis patrimonialista con (uno de los) planteamientos metapatrimonialistas ${ }^{22}$. Como sea, y más allá de las diferencias conceptuales entre ambos grupos de tesis, que el bien jurídico tutelado por los delitos concursales sea individual o supraindividual tiene una importante consecuencia: mientras que los bienes jurídicos individuales son esencialmente disponibles para su titular, ningún individuo tiene capacidad de disponer de un bien jurídico colectivo ${ }^{23-24}$.

El presente trabajo tiene por objeto definir el bien jurídico tutelado por los delitos concursales incorporados al Código Penal chileno a través de la Ley N. ${ }^{\circ} 20.720$ de 2014. Con tal finalidad, el estudio comienza con una revisión crítica de las tesis patrimonialistas y metapatrimonialistas, centrada en las principales objeciones que se han formulado a dichos planteamientos. El análisis culmina con una toma de posición, basada fundamentalmente en la nueva regulación positiva de este grupo de ilícitos, incluyendo tanto los delitos que puede cometer (quien actúe por) la empresa deudora como aquellos que puede llevar a cabo el veedor o liquidador de bienes de dicha empresa.

${ }^{20}$ Corcoy, Mirentxu, cit. (n. 10), pp. 203 y s.

${ }^{21}$ Contador, Nelson - Palacios, Cristián, Procedimientos concursales (Santiago, Thomson Reuters, 2015), pp. 322 y ss.

${ }^{22}$ Entre los exponentes de las tesis mixtas predominan quienes afirman una tutela de intereses patrimoniales y económicos. En esa línea ANTOLISEI, Francesco, Delitos relacionados con las quiebras y las sociedades (traducción de Francisco Bruno y Jorge Guerrero, Bogotá, Editorial Temis, 1964), pp. 21 y ss.; más recientemente CoNTRERAs, Osvaldo, Instituciones de Derecho Comercial (3. ${ }^{a}$ edición actualizada, Santiago, Legal Publishing, 2011), II, p. 1702; Polaino, Miguel - Polaino-OrTs, Miguel, Las insolvencias punibles en la encrucijada del derecho penal y del derecho mercantil: Tras la aprobación de la nueva Ley Concursal española (Bogotá, Universidad Externado de Colombia, Colección de Estudios N. ${ }^{\circ} 32$, 2005), p. 30; TiedemanN, Klaus, Wirtschaftsstrafrecht Besonderer Teil (3. ${ }^{a}$ edición actualizada y ampliada, München, Vahlen, 2011), pp. 249 y s.; indicando que el bien jurídico en sentido técnico sería el patrimonio, mientras que el orden socioeconómico sería el bien jurídico mediato de este grupo de delitos Souto García, Eva María, Frustración de la ejecución e insolvencias punibles (Arts. 257 y ss.), en González Cussac, José Luis (director), Comentarios a la Reforma del Código Penal de 2015 (2. ${ }^{a}$ edición, Valencia, Tirant lo blanch, 2015), p. 755.

${ }^{23}$ Corcoy, Mirentxu, cit. (n. 10), p. 204.

${ }^{24}$ Lo que es sin perjuicio de la existencia de reglas especiales en materia de persecución penal, como las que se aplican a los delitos tributarios y aduaneros, esto es, a delitos que afectan un bien jurídico supraindividual. 


\section{LAS TESIS PATRIMONIALISTAS Y SUS CRÍTICAS}

De acuerdo con las tesis patrimonialistas, los delitos vinculados con el estado de insolvencia inciden negativamente en los acreedores, ya que éstos se ven directamente afectados con la imposibilidad o grave dificultad de perseguir el pago de sus créditos en el patrimonio del deudor. Dicho en otros términos, estas tesis tienen como punto de partida la tutela penal del patrimonio de los acreedores de la empresa deudora ${ }^{25}$, concepto sobre el que, como se sabe, ha existido una extensa controversia. Con todo, en la doctrina chilena ${ }^{26}$ se defiende mayoritariamente un concepto jurídicoeconómico o mixto de patrimonio, según el cual, el patrimonio está integrado por un conjunto de bienes con valor económico que se encuentran bajo el poder de disposición de una persona y respecto de los cuales ella tiene una relación reconocida o al menos no rechazada expresamente por el ordenamiento jurídico.

Ahora bien, el patrimonio es una universalidad jurídica, compuesta por un activo y por un pasivo, y lo que puede resultar afectado por un comportamiento delictivo es el activo de dicha universalidad. De ahí que algunos autores prefieran aludir, no a delitos contra el "patrimonio", sino que, más precisamente, a delitos contra derechos patrimoniale ${ }^{27} \mathrm{O}$ a delitos contra intereses patrimoniales ${ }^{28}$. En esa línea, de acuerdo con una tesis patrimonialista, los delitos concursales serían delitos contra los "intereses patrimoniales" de los acreedores del deudor insolvente.

En relación con los delitos concursales, las tesis patrimonialistas son planteadas en términos todavía más específicos. En ese orden de ideas, se postula que, antes que el (activo del) patrimonio, genéricamente considerado, el bien jurídico tutelado por los delitos vinculados con la insolvencia es "el derecho de crédito del acreedor o acreedores, concretado en el derecho a la satisfacción que tienen sobre el patrimonio del deudor en el caso de que éste incumpla sus obligaciones, como contrapartida del

${ }^{25}$ En ese sentido KINDHÄUSER, Urs, Vor $\iint 283$ bis 283 d, en KindHÄUSER, Urs - Neumann, Ulfrid - Paeffgen, Hans-Ullrich, Nomos Kommentar, Strafgesetzbuch (4. ${ }^{a}$ edición, Baden-Baden, Nomos, 2013), III, nm. 19, nm. 33; también HefendeHL, Roland, Kollektive Rechtsgüter im Strafrecht (Köln, Carl Heymanns Verlag, 2002), pp. 272 y ss.

${ }^{26}$ Por todos Politoff, Sergio - Matus, Jean Pierre - Ramírez, María Cecilia, Lecciones de Derecho Penal Chileno, Parte Especial (reimpresión de la 2. ${ }^{a}$ edición, Santiago, Editorial Jurídica de Chile, 2011), p. 416.

${ }^{27}$ Labatut, Gustavo, Derecho Penal (reimpresión de la 7. a edición actualizada por el profesor Julio Zenteno, Santiago, Editorial Jurídica de Chile, 2012), II, p. 195.

${ }^{28}$ Oliver, Guillermo, Delitos contra la propiedad (Santiago, Legal Publishing, 2013), p. 47. 
deber que tiene el deudor de responder en caso de incumplimiento de sus obligaciones con todos sus bienes presentes o futuros" ${ }^{29}$. En realidad, de acuerdo con las tesis patrimonialistas, los delitos concursales, más que repercutir negativamente en el derecho de crédito de los acreedores, afectan las posibilidades de éstos de hacer efectivos sus créditos en el patrimonio del deudor ${ }^{30}$. En otras palabras, los delitos concursales no incidirían en el derecho de crédito en cuanto tal, que subsiste -formalmente- no obstante la comisión del hecho. Antes bien, dichos delitos afectarían -materialmente- las probabilidades de que los acreedores obtengan el pago de sus respectivos créditos.

Fuera de lo señalado, otra de las particularidades de los delitos vinculados con la insolvencia, desde una perspectiva patrimonialista, sería la posición en la que se ubica el deudor en relación con la administración de sus bienes. En ese sentido, lo característico de estos delitos sería que el deudor afecta intereses ajenos producto de que incide negativamente en su propio patrimonio ${ }^{31}$. De ahí que se postule, en el mismo orden de consideraciones, que este grupo de ilícitos tiende a preservar la integridad del patrimonio del deudor como prenda común de la masa de acreedores ${ }^{32}$.

\section{Argumentos generales contrarios a las tesis patrimonialistas}

Desde un punto de vista general, se critica a las tesis patrimonialistas su incapacidad de fundamentar adecuadamente el injusto de los delitos concursales. Así, se piensa que sustentar el castigo punitivo exclusivamente en la protección penal de intereses patrimoniales resulta insuficiente ${ }^{33}, \mathrm{y}$ puede incluso relativizar el sentido público que tiene el conflicto penal. En la misma línea, si el fundamento del castigo punitivo radica exclusivamente en la afectación del patrimonio de los acreedores a través del comporta-

${ }^{29}$ Muñoz Conde, Francisco, Derecho Penal, Parte Especial (18. a edición revisada y puesta al día, Valencia, Tirant lo Blanch, 2010), p. 458. En la misma línea GonZÁLEZ Cussac, José Luis, Lección XXV, Delitos contra el patrimonio y el orden socioeconómico (VIII): frustración de la ejecución e insolvencias punibles, en GONZÁLEZ CussaC, José Luis (coordinador), Derecho Penal, Parte Especial (4. ${ }^{a}$ edición actualizada a la ley orgánica 1/2015, Valencia, Tirant lo blanch, 2015), pp. 436 y s.

${ }^{30}$ Vargas Sielfeld, Nadín, Los delitos concursales del deudor (memoria inédita, Pontificia Universidad Católica de Valparaíso, Valparaíso, 2015), pp. 8 y ss.

${ }^{31}$ Krause, Daniel-Marcus, Ordnungsgemäßes Wirtschaften und Erlaubtes Risiko (Berlin, Duncker \& Humblot, 1995), p. 183; también Monge Fernández, Antonia, El delito concursal punible tras la reforma penal de 2015 (Análisis de los artículos 259 y 259 bis CP) (Valencia, Tirant lo Blanch, 2016), p. 58.

32 Erbetta, Daniel, Delitos de insolvencia (Buenos Aires, Hammurabi, 2009), p. 128, p. 130.

${ }^{33}$ En ese orden de ideas Bustos, Juan, cit. (n. 4), p. 37. 
miento del deudor, podría llegar a concluirse que no existen motivos de peso que justifiquen esa forma de sanción frente a otras menos gravosas (principalmente administrativas y civiles).

Vinculado con lo anterior, se dice que el castigo punitivo de la afectación de los intereses patrimoniales de los acreedores frente al estado de insolvencia del deudor, no hace sino encubrir un supuesto de prisión por deudas ${ }^{34}$, actualmente proscrita por el artículo $7 .^{\circ}$ número 7 de la Convención Americana sobre Derechos Humanos. En otros términos, los delitos vinculados con la insolvencia sancionarían, en el fondo, el incumplimiento de parte del deudor de su obligación de satisfacer los créditos de sus acreedores. En este caso, la única diferencia con el incumplimiento de las demás obligaciones civiles radicaría en la pluralidad de personas afectadas y en el hecho de que la insolvencia constituye un estado patrimonial crítico que, como tal, se caracteriza por tener una cierta permanencia en el tiempo. Salvo esos matices, los delitos concursales no serían más que supuestos de incumplimiento contractual, sancionados punitivamente.

\section{Argumentos especificos contrarios a las tesis patrimonialistas}

Desde un punto de vista específico, se afirma que a la modificación del Párrafo $7^{\circ}$ del Título IX del Libro II CP. subyacería la tutela de intereses que van más allá de los estrictamente patrimoniales. En ese orden de ideas, se plantea que mientras antes de la reforma introducida por la Ley ${ }^{\circ}{ }^{\circ}$ 20.720 aquél se intitulaba "De las defraudaciones", hoy su denominación es "De los delitos concursales y de las defraudaciones", producto de la consideración de los procedimientos concursales y de "un aspecto colectivo que excede el patrimonio del acreedor" 35 .

Igualmente, se destaca lo curioso que resulta que los delitos vinculados con la insolvencia no tengan una referencia cuantitativa específica al perjuicio patrimonial en la estructura típica o en las reglas de determinación de la pena. Con ello, este grupo de delitos se alejaría de la tipificación penal de otras figuras del Título IX del Libro II del CP., como los hurtos y las estafas que, entre otras cosas, hacen depender la pena aplicable de la cuantía de la cosa o del monto de lo defraudado, respectivamente ${ }^{36}$.

Relacionado con lo anterior, se esgrime lo difícil que resulta justificar la identidad penológica en abstracto de un delito concursal de bagatela

34 Bustos, Juan, cit. (n. 4), p. 37.

35 Vargas Pinto, Tatiana, Nuevo régimen punitivo concursaly sus principales desafíos, en Jequier Lehuedé, Eduardo (editor), Estudios de Derecho Concursal, La Ley $N^{\circ} 20.720$, a un año de su vigencia (Santiago, Thomson Reuters, 2016), p. 200.

36 Con alusión a la normativa penal española Caballero, Felipe, cit. (n. 18), pp. 94 y s. 
frente a uno cuantioso. En esa línea, se plantea que el bien jurídico tutelado en uno y otro caso sería algo que va más allá del patrimonio, y que se ve igualmente afectado tratándose de delitos que involucran tanto pequeñas como grandes sumas dinerarias ${ }^{37}$.

De otro lado, se critica a las tesis patrimonialistas las limitaciones que pretenden imponer a la libertad de disposición que el propietario tiene sobre los bienes que conforman su patrimonio ${ }^{38}$. En ese sentido, tales restricciones subyacerían a los planteamientos que buscan tutelar el interés de los acreedores de que la empresa deudora se abstenga de realizar comportamientos que provoquen o agraven su insolvencia, en el entendido de que éstos inciden negativamente en las posibilidades de que los primeros obtengan el pago de sus respectivos créditos $^{39}$.

\section{LAS TESIS METAPATRIMONIALISTAS Y SUS CRÍTICAS}

Las tesis metapatrimonialistas presentan diversas variantes, destacando las que postulan una protección punitiva de la fe pública, de la administración de justicia o del orden público económico. De acuerdo con todas ellas, los delitos vinculados con el estado de insolvencia inciden negativamente en la sociedad en general ${ }^{40}$, en la medida en que provocan una importante alteración de la fe pública ${ }^{41}$, de la administración de justicia ${ }^{42}$ o del orden público económico ${ }^{43}$, respectivamente.

El concepto de fe pública es entendido, en relación con los delitos

${ }^{37}$ Con referencia expresa al delito de alzamiento de bienes Caballero, Felipe, cit. (n. 18), p. 96.

${ }^{38}$ En esa línea Bustos, Juan, cit. (n. 4), p. 36, p. 56.

39 En ese sentido Caballero, Felipe, cit. (n. 18), p. 86 con referencias ulteriores.

${ }^{40}$ Contador, Nelson - Palacios, Cristián, cit. (n. 21), pp. 322 y s. con referencias ulteriores.

${ }^{41}$ Como exponente de esta teoría está el pensamiento de Carrara, Francesco, Programa de Derecho Criminal, Parte Especial (traducción de José Ortega y Jorge Guerrero, Bogotá, Editorial Temis, 1964), VII, p. 53, para quien “(...) la bancarrota de un comerciante (...) ocupa su verdadero sitio entre los delitos sociales contra la fe pública" (cursivas en el original).

${ }^{42}$ Entre los partidarios de este planteamiento pueden citarse Mir PUIG, Santiago - Gallego Soler, José Ignacio, Responsabilidad civil derivada de los delitos de alzamiento, en López Barja de Quiroga, Jacobo - Zugaldía Espinar, José Miguel (coordinadores), Dogmática y ley penal, Libro Homenaje a Enrique Bacigalupo (Madrid - Barcelona, Marcial Pons, 2004), II, p. 1083, n. 16, con referencia expresa a los casos de insolvencia parcial y ficticia.

${ }^{43}$ Como exponente de esta teoría está el pensamiento de Bustos, Juan, cit. (n. 4), pp. 54 y s., para quien el delito de quiebra constituye el delito económico por excelencia. 
concursales, como sinónimo de buena fe o de confianza comercial ${ }^{44}$. La noción de administración de justicia, en cambio, puede ser definida en sentido funcional, como una actividad de aplicación de la ley en la resolución de conflictos, ejercida con independencia y sumisión a la ley, en virtud de la cual las decisiones adquieren el valor de cosa juzgada ${ }^{45}$. Por su parte, el orden económico u orden público económico puede ser conceptualizado en términos restringidos o en términos amplios ${ }^{46}$. Desde un punto de vista restringido, el orden económico es "el conjunto de normas jurídico-penales que protegen la actividad interventora y reguladora del Estado en la economía"; mientras que desde un punto de vista amplio, el orden económico se identifica con "la regulación jurídica de las actividades de producción, distribución y consumo de bienes y servicios" "47. Ahora bien, normalmente la doctrina es más específica y señala que lo protegido por los delitos vinculados con la insolvencia no es el orden público económico en alguna de las dos acepciones antes referidas, sino que, más específicamente, el "sistema económico crediticio" 48 . Por lo mismo, las referencias que en lo sucesivo se hagan al orden público económico implicarán también dicho bien jurídico particular, en el entendido de que el primero (sistema económico crediticio) forma parte del segundo (orden público económico).

Pues bien, más allá del significado concreto que pueda atribuirse a los conceptos de fe pública, de administración de justicia o de orden público económico, existen importantes razones, ya sean generales o específicas, para cuestionar los planteamientos metapatrimonialistas. Y dichos cuestionamientos se hacen extensivos tanto a las tesis metapatrimonialistas puras como a las denominadas tesis mixtas ${ }^{49}$, ya que las primeras y las segundas defienden, de una u otra manera, un postulado metapatrimonialista.

\section{Argumentos generales contrarios a las tesis metapatrimonialistas}

${ }^{44}$ Caballero, Felipe, cit. (n. 18), p. 106.

45 Rodríguez Collao, Luis - Ossandón Widow, Magdalena, Delitos contra la función pública (reimpresión de la 2. ${ }^{\text {a }}$ edición actualizada, Santiago, Editorial Jurídica de Chile, 2011), p. 162.

${ }^{46}$ Para el análisis de dichos conceptos véase, por ejemplo, Tiedemann, Klaus, El concepto de derecho económico, de derecho penal económico y de delito económico, en Revista Chilena de Derecho 10 (1983), pp. 67 y s.

${ }^{47}$ Rodríguez Collao, Luis - Ossandón Widow, Magdalena, Delitos aduaneros (Santiago, Editorial Jurídica de Chile, 2010), p. 78.

${ }^{48}$ Bustos, Juan, cit. (n. 4), p. 52; similar Queralt, Joan, Derecho Penal Español, Parte Especial (7. ${ }^{a}$ edición revisada y actualizada, Valencia, Tirant lo Blanch, 2015), p. 791.

${ }^{49}$ Véase el punto I. 
En relación con el sentido supraindividual del objeto de tutela, es común que se indique que los delitos vinculados con la insolvencia pueden afectar a un gran número de personas (por ejemplo, los múltiples proveedores y trabajadores de la empresa que se encuentra en situación de insolvencia ${ }^{50}$ ), personas que, ciertamente, exceden a los acreedores de dicho deudor. Esta idea, si bien es correcta, puede ser fuente de equívocos, en el sentido de que terminen confundiéndose "los efectos sociales del comportamiento prohibido" con "[el] bien jurídico en sentido técnico" 51 y su carácter individual o supraindividual. En esa línea, es posible que el homicidio de una persona concreta incida negativamente en muchas otras (en el ejemplo indicado, el homicidio del dueño de una empresa puede afectar a muchos proveedores, así como a los trabajadores de la misma), pero de ello no puede seguirse que el bien jurídico subyacente al homicidio sea un interés de carácter colectivo.

Ahora bien, probablemente uno de los aspectos que ha conspirado en contra del posible sentido supraindividual del bien jurídico de los delitos concursales dice relación con la gran variedad de supuestos que pueden catalogarse de tales, y que abarcan insolvencias de gran, mediana y pequeña entidad ${ }^{52}$. Sobre todo estas últimas parecen contrarias a la idea de que los delitos concursales afecten siempre a un gran número de personas o que tengan siempre nefastas consecuencias en nuestro sistema jurídico y económico. Y si ello es efectivo, podría ocurrir que no se cumpla con el principio de ofensividad, según el cual, el castigo penal se encuentra supeditado a la afectación de un bien jurídico; y que, por lo mismo, no pueda sancionarse el comportamiento realizado por el deudor, por no incidir negativamente en el bien jurídico supraindividual supuestamente tutelado ${ }^{53}$.

Frente a ello, la doctrina se ha visto en la obligación de postular que los delitos concursales sólo tienen un sentido macrosocial o colectivo cuando son cometidos por empresas o empresarios que ostentan una posición de poder de la que abusan al interior del mercado ${ }^{54}$. En consecuencia, de acuerdo con este planteamiento, el carácter colectivo de los

${ }^{50}$ Ortiz, Luis, Delincuencia económica, en Problemas Actuales de Derecho Penal (Temuco, Universidad Católica de Temuco, 2003), p. 195. Véase también Queralt, Joan, cit. (n. 48), p. 791.

51 Navas, Iván, Insolvencias punibles: Fundamentos y limites (Madrid, Marcial Pons, 2015), p. 44.

${ }^{52}$ En ese sentido Fejjoo Sánchez, Bernardo, Cuestiones actuales de Derecho Penal Económico (Montevideo - Buenos Aires, B de f, 2009), pp. 152 y s.

${ }^{53}$ Vargas Sielfeld, Nadín, cit. (n. 30), p. 10.

${ }^{54}$ Sandoval, Ricardo, Reorganización y liquidación de empresas y personas. Derecho concursal (reimpresión de la 7. edición, Santiago, Editorial Jurídica de Chile, 2015), pp. 443 y s. 
delitos concursales no se vincularía necesariamente con el número o la categoría de víctimas que ellos afectarían, sino que se relacionaría con las particularidades que asume la conducta (abusiva) del agente del delito, supuesto que éste tenga una cierta relevancia al interior del mercado. El problema de este razonamiento es que hace depender la ofensividad de los delitos concursales fundamentalmente de una variable subjetiva, en concreto, de un comportamiento contingente y cuya ejecución depende del (específico) hechor que lo lleve a cabo. En el mismo orden de ideas, el bien jurídico tutelado por los delitos concursales debe identificarse con un interés que siempre resulte afectado con el comportamiento típico, no así con un interés que pueda llegar a vulnerarse frente a supuestos bien determinados ${ }^{55}$.

\section{Argumentos especificos contrarios a las tesis metapatrimonialistas}

Por una parte, sostener que la fe pública es el bien jurídico protegido por los delitos concursales enfrenta una dificultad sistemática difícil de soslayar. En efecto, los delitos concursales se encuentran ubicados fuera del Título IV del Libro II CP. (De los crímenes y simples delitos contra la fe pública, de las falsificaciones, del falso testimonio), lo que constituye un primer argumento para rechazar que sea la fe pública el bien jurídico tutelado por dichos ilícitos. Además, incluso si se considerara que el concepto de fe pública en materia de delitos concursales "no debe entenderse en su sentido técnico de veracidad o autenticidad jurídica" ${ }^{56}$, a diferencia de lo que ocurre con los delitos del Título IV del Libro II CP., la idea de fe pública, de buena fe o de confianza comercial se caracteriza por una "generalidad y abstracción" 57 que impide precisar adecuadamente el objeto de protección penal de este grupo de delitos y dificulta considerablemente que éste pueda cumplir las funciones que suelen atribuirse al concepto de bien jurídico. Finalmente, se indica que la idea de fe pública o de confianza comercial como objeto de protección de los delitos vinculados con la insolvencia tuvo sentido en un contexto histórico y económico crediticio caracterizado por el vínculo entre personas físicas y no por la existencia de "contactos sociales estereotipados y anónimos" como son los que se verifican actualmente ${ }^{58}$.

${ }^{55}$ En ese orden de ideas, a propósito del alzamiento de bienes, NAVAs, Iván, cit. (n. 51), p. 45: “(...) que la afectación de aquello que se denomina sistema económico sea posible no puede dar lugar a asegurar que la protección penal del alzamiento de bienes posee un aspecto supraindividual".

${ }^{56}$ Caballero, Felipe, cit. (n. 18), p. 106.

${ }^{57}$ Caballero, Felipe, cit. (n. 18), p. 109.

${ }^{58}$ Navas, Iván, cit. (n. 51), p. 51. 
Por otra parte, afirmar que la administración de justicia es el bien jurídico tutelado por los delitos concursales afronta similares problemas sistemáticos, pues dichos ilícitos se encuentran regulados fuera del Título IV del Libro II CP. (De los crímenes y simples delitos contra la fe pública, de las falsificaciones, del falso testimonio) y del Título $\mathrm{V}$ del mismo Libro (De los crímenes y simples delitos cometidos por empleados públicos en el desempeño de sus cargos), que es donde fundamentalmente se regulan los delitos contra la administración de justicia. A lo dicho se añade que algunos delitos concursales suponen que se verifique un comportamiento con anterioridad a la existencia de un procedimiento concursal ${ }^{59}$, concretamente, dentro de los dos años previos a la resolución de reorganización o liquidación ${ }^{60}$, circunstancia que dificulta plantear que sea la administración de justicia el bien jurídico común a todos ellos. Por último, se agrega que la administración de justicia o, más específicamente, el proceso de ejecución, "no es sino el medio o instrumento para salvaguardar el verdadero sustrato que está detrás de la relación acreedor-deudor y que no es otro que el crédito como elemento patrimonial"'61.

En fin, señalar que el orden público económico es el bien jurídico protegido por los delitos concursales enfrenta las críticas que suelen formularse a la noción de "orden público económico" como objeto de tutela penal. En ese sentido, no obstante los esfuerzos que ha realizado la doctrina a fin de dotar de contenido al concepto de orden público económico, así como a diferenciar una vertiente restringida y una amplia de dicho término, a éste sigue achacándosele una cierta dosis de ambigüedad e indeterminación ${ }^{62}$. En la misma línea, la doctrina destaca que la amplitud del término "orden económico" ha hecho perder al Derecho penal económico en precisión conceptual todo lo que ha ganado en importancia cuantitativa ${ }^{63}$.

Vinculado con lo anterior, un sector de la doctrina plantea que en los

${ }^{59}$ En esa línea Navarro, Guillermo Rafael - Rizzi, Aníbal Horacio, El delito de quiebra (Buenos Aires, Hammurabi, 2004), p. 23.

${ }^{60} \mathrm{~V}$. gr., el delito de provocación o agravación de la insolvencia del artículo 463 $\mathrm{CP}$., que debe cometerse dentro de los dos años anteriores a la resolución de liquidación; o el delito de ocultamiento de bienes o haberes del artículo 463 bis número 1 CP., que debe llevarse a cabo dentro de los dos años anteriores a la resolución de reorganización o liquidación.

${ }^{61}$ Navas, Iván, cit. (n. 51), p. 54.

${ }^{62}$ En ese sentido, por ejemplo, Ortiz, Luis, cit. (n. 50), p. 200. Con alusión específica a la indeterminación del concepto de "economía crediticia" NAVAs, Iván, cit. (n. 51), p. 45 con referencias ulteriores.

${ }^{63}$ Cervini, Raúl, Aproximación conceptual integrada al derecho penal económico, en RUbinska, Ramiro M. - Schurjin Almenar, Daniel (coordinadores), Derecho penal económico (Buenos Aires, Marcial Pons, 2010), I, p. 35. 
denominados delitos económicos la economía o el orden público económico sólo constituye un "bien jurídico mediato genérico, integrado en la ratio legis", no así un "bien jurídico específico en sentido técnico" "64. Frente a ello se ha replicado, con razón, que en los delitos relacionados con la insolvencia no queda clara la función dogmática de este supuesto bien jurídico mediato ${ }^{65}$ que, a diferencia del bien jurídico técnico, no tendría que ser lesionado ni puesto en peligro ${ }^{66}$. En la misma línea, también se ha sostenido -y ello puede extenderse a todas las tesis metapatrimonialistas-, que no parece necesario recurrir a una referencia supraindividual como la indicada para fundamentar la reacción punitiva, toda vez que "la protección del patrimonio individual del acreedor posee ya bastante fuerza y está dotada de suficiente contenido material para justificar la intervencin del Derecho penal frente a insolvencias fraudulentas". la intervencifuncis con la insolvencia sers particularidades propias, són del Derecho penal frente a insolvencias fraudulentas" ${ }^{\prime 67}$.

Finalmente ¿Tiene consecuencias relevantes para la interpretación y aplicación práctica de un comportamiento delictivo el hecho que éste sea calificado de delito económico? En ese sentido, a diferencia de lo que ocurre en la legislación española, que contempla una pena agravada para el caso que una insolvencia punible produzca o pueda producir perjuicio patrimonial en una generalidad de personas o pueda ponerlas en una grave situación económica (artículo 259 bis $1^{\text {a }}$ CP. español), el CP. chileno no prevé una agravación semejante de la penalidad aplicable. En otras palabras, la legislación chilena no consagra distinciones, desde el punto de vista de la conminación abstracta de la pena, entre un delito contra intereses patrimoniales que afecta a una sola persona (por ejemplo, una estafa individual) $\mathrm{y}$ un delito contra intereses patrimoniales que incide negativamente en grandes sectores de la población (v. gr., una estafa colectiva) y, con ello, también en el sistema económico.

Asimismo, si bien podría estimarse que la calificación de un delito concursal como delito económico tiende a una interpretación restrictiva del tipo, en el sentido de que éste únicamente se aplicaría si afecta al orden público económico, tal interpretación no parece tener un respaldo en las normas que regulan este grupo de ilícitos. En ese sentido, si se

${ }^{64}$ En relación con los delitos económicos en sentido amplio Martínez-BuJÁn Pérez, Carlos, Derecho Penal Económico, Parte General (Valencia, Tirant lo Blanch, 1998), p. 97; asimismo, respecto de los delitos económicos en sentido estricto, ibídem p. 98.

${ }^{65}$ Navas, Iván, cit. (n. 51), p. 45.

${ }^{66}$ En ese orden de ideas Souto García, Eva María, cit. (n. 22), p. 755.

${ }^{67}$ Navas, Iván, cit. (n. 51), p. 46. 
examinan las diversas conductas que pueden calificarse de tales, no se divisan elementos en la descripción de los comportamientos que apunten a excluir la aplicación de aquellos delitos concursales que "sólo" inciden negativamente en el patrimonio de los acreedores de la empresa deudora, en comparación con aquellos que "además" afectarían la economía o el orden público económico ${ }^{68}$.

De otro lado, las agravantes genéricas del artículo 12 CP., en términos generales, no parecen aplicables a hipótesis en que, junto con la afectación de intereses patrimoniales, se incida negativamente en la economía o en el orden público económico. En esa línea, la única agravante de dicho artículo que, en principio, podría tener aplicación es la contenida en el número 4 de dicho precepto. Como se sabe, ésta supone "[a]umentar deliberadamente el mal del delito causando otros males innecesarios para su ejecución"; y ya que no aparece expresamente limitada a los delitos contra las personas - a diferencia de otras agravantes reguladas en el mismo artículo- podría llegar a aplicarse a cualquier figura delictiva $\mathrm{y}$, consiguientemente, también a los delitos concursales. Con todo, de aceptarse que la ejecución de estos últimos (además) afecta a la economía o al orden público económico, estaremos ante casos en que la conducta misma incidirá negativamente en dicho interés, y no frente a supuestos en que con ella se aumente deliberadamente el mal del delito "causando otros males innecesarios" para su ejecución. De suerte que la aplicación de la referida agravante tampoco parece factible.

Consiguientemente, más allá del recurso -siempre posible- al artículo 69 CP., que prescribe tener en cuenta, al determinar la cuantía exacta de la pena, "la mayor o menor extensión del mal producido por el delito" "69" la categorización de los delitos concursales como figuras integrantes del derecho penal económico parece - al menos por ahora-condenada a tener limitadas repercusiones prácticas.

\section{TOMA DE POSICIÓN}

Los delitos concursales regulados en el CP. tutelan intereses patri-

${ }^{68}$ Como plantea Fejjoo Sánchez, Bernardo, cit. (n. 52), pp. 152 y s., "sigue existiendo en el marco del Derecho vigente un delito concursal aunque sólo se pueda constatar una lesión patrimonial o aunque se trate de una insolvencia de entidad insuficiente para afectar de alguna manera al sistema crediticio".

${ }^{69}$ En esa línea, a propósito de la estafa, véase MAYer Lux, Laura - Fernandes Godinho, Inês, La estafa como delito económico, en Revista de Derecho de la Pontificia Universidad Católica de Valparaíso XLI (2013), pp. 204 y s. Para el análisis crítico de un razonamiento similar respecto de las insolvencias punibles, con referencia a la legislación española, véase NAvAs, Iván, cit. (n. 51), p. 46. 
moniales, concretamente, las posibilidades de los acreedores de hacer efectivos sus créditos en el patrimonio del deudor. Esta afirmación se sustenta en dos órdenes de consideraciones. Por una parte, las críticas que se plantean a las tesis patrimonialistas no resultan insuperables, a diferencia de lo que ocurre con las objeciones que se formulan a las tesis metapatrimonialistas, sea en sus variantes puras o mixtas. Por otra parte $-y$ esto es lo fundamental-, la actual regulación de los delitos concursales contiene poderosos argumentos en favor de las tesis patrimonialistas.

1. La superación de los argumentos generales y especificos contrarios a las tesis patrimonialistas

De acuerdo con lo indicado supra ${ }^{70}$, se critica a las tesis patrimonialistas su incapacidad de fundamentar adecuadamente el injusto de los delitos concursales pues, en el fondo, el castigo de éstos se sustentaría exclusivamente en la afectación de intereses patrimoniales, que perfectamente podrían tutelarse a través de mecanismos menos gravosos que la pena. Relacionado con ello, se sostiene que castigar penalmente la afectación de tales intereses frente a la insolvencia de la empresa deudora no haría sino encubrir un supuesto de prisión por deudas. Para superar estas críticas debe partirse de la base de que, efectivamente, a diferencia de otros bienes jurídicos individuales como la vida, la salud o la libertad, la sola afectación del patrimonio no es suficiente para fundamentar el injusto de un determinado delito o grupo de delitos ${ }^{71}$. Antes bien, se requiere la provocación de un menoscabo patrimonial (desvalor de resultado) a través de medios que se consideran particularmente graves (desvalor de acción). Por lo mismo, tratándose de los delitos concursales, el fundamento del injusto y de su consecuente castigo también tendrá que vincularse, copulativamente, con la afectación de los intereses patrimoniales de los acreedores (desvalor de resultado) mediante la ejecución de comportamientos delictivos de especial gravedad (desvalor de acción). En la misma línea, en los delitos vinculados con la insolvencia no se trata de sancionar el mero hecho de contraer deudas o el mero estado de insolvencia ${ }^{72}$, sino que de castigar penalmente una insolvencia "deliberadamente provocada o intencionalmente agravada" 73 por el deudor, que deja a los acreedores en una situación de

${ }^{70}$ Véase el punto II. 1.

71 Así Bustos, Juan, cit. (n. 4), p. 35.

${ }^{72}$ Bustos, Juan, cit. (n. 4), p. 36, quien, en todo caso, efectúa esta acotación para abonar la tesis metapatrimonialista del bien jurídico por él defendida.

${ }^{73}$ Contador, Nelson - Palacios, Cristián, cit. (n. 21), p. 322; así también Feijoo SÁNCHEZ, Bernardo, cit. (n. 52), p. 158. 
desvalimiento frente al primero ${ }^{74}$. Dicha circunstancia permite destacar el carácter fraudulento del comportamiento, así como sustentar el injusto de los delitos concursales en algo que exceda la mera prisión por deudas.

Igualmente, según lo afirmado supra ${ }^{75}$, el cambio en la denominación del Párrafo $7^{\circ}$ del Título IX del Libro II CP. -que "De las defraudaciones" pasó a llamarse "De los delitos concursales y de las defraudaciones"-, expresaría una consideración por los procedimientos concursales y por un aspecto colectivo que excedería los intereses estrictamente patrimoniales de los acreedores. En efecto, la modificación del título de dicho Párrafo se hace cargo de la existencia de procedimientos concursales, en tanto presupuesto de los diversos delitos concursales reglados en el mismo. Sin embargo, de la consideración de dichos procedimientos no se sigue la tutela de intereses que son de titularidad o sirven a la generalidad de las personas que integran el cuerpo social (o sea, de bienes jurídicos colectivos o supraindividuales). Por el contrario, ella sólo pone de manifiesto la protección de intereses jurídico penales en un determinado contexto: la verificación de un procedimiento concursal. Asimismo, y en la línea de lo señalado supra ${ }^{76}$, la afectación de un gran número de personas -en este caso, (el concurso de) los acreedores-, en cuanto tal, no altera la naturaleza individual del objeto de protección de los delitos concursales.

Por su parte, se objeta a las tesis patrimonialistas que no se hagan cargo de la falta de referencias cuantitativas específicas al daño patrimonial en la estructura típica o en las normas que establecen la penalidad aplicable de los tipos vinculados con la insolvencia. En realidad, esta objeción puede superarse si se tienen en cuenta las disposiciones que regulan los

${ }^{74}$ Bustos, Juan, cit. (n. 4), p. 38, quien, sin embargo, critica dicho planteamiento, por estimar que de acuerdo con el mismo el delito de quiebra implicaría un abuso o una conducta fraudulenta que impediría distinguirlo de otros delitos contra intereses patrimoniales como la estafa, el abuso de firma en blanco o la simulación de contratos. En realidad, ello no es exacto. Por una parte, es cierto que, de acuerdo con una tesis patrimonialista, los delitos concursales pasan a incluirse dentro de los delitos contra intereses patrimoniales, entre los que se cuentan todos los ejemplos indicados (estafa, abuso de firma en blanco, simulación de contratos). No obstante, en todos ellos el medio de comisión del delito es diverso. Por otra parte, la situación de desvalimiento en que el deudor dejaría a sus acreedores puede ser considerada como un injusto específico y particular de los delitos concursales, que no está (necesariamente) presente en otras defraudaciones del Título IX del Libro II CP.; mientras que la insolvencia "deliberadamente provocada o intencionalmente agravada" puede implicar una mayor reprochabilidad, tampoco presente en otras defraudaciones del referido Título.

${ }^{75}$ Véase el punto II. 2.

${ }^{76}$ Véase el punto III. 1. 
delitos contra intereses patrimoniales en el CP. Por una parte, los delitos relacionados con la insolvencia sí tienen alusiones al perjuicio patrimonial en la estructura típica. Es cierto que muchas de esas referencias no pueden interpretarse, técnicamente, como una exigencia de perjuicio patrimonial en tanto elemento del tipo. Pero también es efectivo que en los delitos vinculados con la insolvencia se contienen alusiones de claro contenido patrimonial, que apuntan, en términos generales, a la realización de comportamientos defraudatorios en contra de los acreedores de la empresa deudora. Por otra parte, la referencia cuantitativa específica al daño patrimonial en las normas que establecen la penalidad aplicable no se contempla en figuras que evidentemente afectan intereses patrimoniales ajenos, como es el caso de la estafa residual del artículo 473 CP. De suerte que no es posible sostener, de acuerdo con la normativa penal chilena, que sólo son delitos contra dichos intereses aquellos cuya pena depende de la cuantía de la cosa apropiada o del fraude causado.

Asimismo, se critica a las tesis patrimonialistas su incapacidad de justificar la identidad penológica en abstracto de un delito concursal de bagatela frente a uno cuantioso. Efectivamente, esa es una dificultad que enfrentan aquellos delitos contra intereses patrimoniales que no hacen depender la pena aplicable de la cuantía del daño irrogado. Para superar en parte ese inconveniente, en materia de delitos concursales es posible recurrir a dos órdenes de consideraciones. De un lado, puede favorecerse una interpretación restrictiva de este grupo de ilícitos que, tomando en cuenta el bien jurídico tutelado, se centre en la idea de "desvalimiento de los acreedores". Así, por ejemplo, si se considera el delito del artículo 463 CP., que exige ejecutar actos o contratos que disminuyan el activo o aumenten el pasivo de la empresa deudora, sin otra justificación económica o jurídica que la de perjudicar a los acreedores, dentro de los dos años anteriores a la resolución de liquidación, no bastará con una disminución o un aumento irrelevante del activo o del pasivo, respectivamente. Por el contrario, para aplicar dicho delito, se requerirá que la disminución del activo o el aumento del pasivo del deudor afecte gravemente las posibilidades de los acreedores de hacer efectivos sus créditos en el patrimonio del primero. De otro lado, puede recurrirse a lo dispuesto en el artículo 69 CP. que, como ya se señaló, prescribe tener en cuenta, al determinar la cuantía exacta de la pena, "la mayor o menor extensión del mal producido por el delito". Gracias a ello puede morigerarse el establecimiento de penas en abstracto idénticas para hipótesis que, desde el punto de vista de la afectación del bien jurídico, son (considerablemente) diversas.

Finalmente, se reprocha a las tesis patrimonialistas las limitaciones que pretenden imponer a la libertad de disposición que el propietario tiene 
sobre los bienes que conforman su patrimonio. Pues bien, aunque sea una obviedad, el Derecho penal impone constantemente restricciones a nuestra actuación, sobre la base de que ciertos comportamientos, que en principio son perfectamente lícitos, puedan llegar a dañar intereses (penalmente relevantes) de terceros. En ese sentido, para concluir la legitimidad de la limitación establecida respecto de tal o cual actuación, no basta con determinar que dicha actuación es (en principio) lícita: de lo que se trata es de definir si esa actuación (en principio) lícita debe prohibirse parcial o totalmente por las consecuencias negativas que importa para terceros, definición en la que, ciertamente, operará un juicio de ponderación. En la misma línea, la propia Ley N. ${ }^{\circ} 20.720$ establece restricciones a la libertad de disposición, que pueden ser parciales o totales, según exista un procedimiento de reorganización o de liquidación de la empresa deudora.

2. El fortalecimiento de los argumentos favorables a las tesis patrimonialistas producto de los cambios introducidos por la Ley $N^{\circ} 20.720$

En favor de las tesis patrimonialistas puede indicarse, en primer término, la ubicación sistemática que actualmente tienen los delitos concursales, dentro del Título IX del Libro II del CP. (Crímenes y simples delitos contra la propiedad $)^{77}$, cuya rúbrica ha sido interpretada tradicionalmente en términos amplios. En ese sentido, se entiende que la noción penal de propiedad abarca una serie de relaciones jurídicas, entre las que se cuentan el dominio, así como los demás derechos reales, pero también los derechos personales o créditos e incluso la posesión y la mera tenencia ${ }^{78}$. Vinculado con ello está el hecho que el legislador chileno hasta ahora no ha optado por utilizar una denominación para el Título IX del Libro II CP. que sugiera la tutela de un interés que vaya más allá de lo patrimonial, como sí ocurre en el CP. español, que dedica el Título XIII a los Delitos contra el patrimonio y contra el orden socioeconómico. Ahora bien, es cierto que la ubicación sistemática y la denominación del Título en el que se encuentra un delito o grupo de delitos no siempre son determinantes del bien jurídico tutelado, pero también es efectivo que pueden ser tenidas como un primer indicio para la delimitación del objeto de tutela penal ${ }^{79}$.

77 Bawlitza, Cristián, Delitos concursales, en Balmaceda, Gustavo, Manual de Derecho Penal, Parte Especial (Santiago, Librotecnia, 2014), p. 371. En igual sentido, a propósito de la normativa argentina, Navarro, Guillermo Rafael - Rizzi, Aníbal Horacio, cit. (n. 59), pp. 21 y ss.; asimismo, respecto de la legislación portuguesa, Caeiro, Pedro, Sobre a natureza dos crimes falenciais (o património, a falência, a sua incriminação e a reforma dela) (Coimbra, Coimbra Editora, 1996), p. 19.

${ }^{78}$ Etcheberry, Alfredo, cit. (n. 14), III, p. 288.

79 Vargas Sielfeld, Nadín, cit. (n. 30), p. 9. 
Igualmente, la descripción típica de los delitos concursales contiene elementos que hablan en favor de una tesis patrimonialista. En ese orden de ideas, como ya se indicó, el artículo 463 CP. requiere ejecutar actos o contratos que disminuyan el activo o aumenten el pasivo de la empresa deudora, sin otra justificación económica o jurídica que la de perjudicar a los acreedores, dentro de los dos años anteriores a la resolución de liquidación. Pues bien, dicha norma, que encabeza el conjunto de delitos concursales tipificados en el CP., se refiere al perjuicio para los acreedores, exigencia que, más allá de su naturaleza jurídica, alude inequívocamente a los intereses patrimoniales de quienes tienen un crédito en contra de la empresa deudora. Algo parecido puede decirse de los delitos de los artículos 463 bis y 463 ter CP., que afectan bienes del deudor sobre los que podría perseguirse el pago (que se ocultan, son objeto de distracción o de disposición); o bien, dificultan o impiden determinar el activo o pasivo del deudor, respectivamente. En la misma línea, los delitos concursales que tienen como sujeto activo al deudor hacen mención expresa a los "acreedores" o implican conceptualmente la existencia de tales acreedores, lo que es demostrativo de que son los derechos o intereses de dichos acreedores y las posibilidades de verlos satisfechos el bien jurídico tutelado ${ }^{80}$.

La situación no varía tratándose de los delitos concursales que puede cometer el veedor o liquidador de bienes. En efecto, el CP. castiga las conductas consistentes en apropiarse de bienes del deudor (artículo 464 número 1); defraudar a los acreedores, alterando en sus cuentas de administración los valores obtenidos en el procedimiento concursal, suponiendo gastos o exagerando los que hubiere hecho (artículo 464 número 2); proporcionar ventajas indebidas a un acreedor, al deudor o a un tercero (artículo 464 número 3); o bien, distraer bienes del deudor (artículo 464 bis); todos los cuales apuntan a afectar las posibilidades de los acreedores de hacer efectivos sus créditos en el patrimonio de la empresa deudora.

A lo dicho puede agregarse que, de acuerdo con el artículo 465 CP., los delitos contemplados en el Párrafo $7^{\circ}$ del Título IX del Libro II CP. están consagrados como figuras de acción penal pública previa instancia particular y respecto de las cuales procede la celebración de acuerdos reparatorios de conformidad al artículo 241 y siguientes del CPP., lo que habla en favor de la tutela de intereses patrimoniales (individuales) y no de un bien jurídico colectivo como la fe pública, la administración de justicia o el orden público económico. En efecto, el referido artículo 241 CPP., que regla la procedencia de tales acuerdos, señala en su inciso segundo: 'Los acuerdos reparatorios sólo podrán referirse a hechos investigados que afectaren

${ }^{80}$ Vargas Sielfeld, Nadín, cit. (n. 30), p. 9. 
bienes jurídicos disponibles de carácter patrimonial, consistieren en lesiones menos graves o constituyeren delitos culposos”. Ahora bien, de todas esas categorías delictivas la única que resulta compatible con el sentido y la regulación de los delitos concursales que puede cometer el deudor es la relativa a “bienes jurídicos disponibles de carácter patrimonial". Por tanto, en los delitos concursales se contemplaría una posibilidad específica de celebrar acuerdos reparatorios, de conformidad al artículo 241 y siguientes del CPP., referidos a un bien jurídico disponible de carácter patrimonial: los intereses patrimoniales de los acreedores ${ }^{81}$.

En relación con esto último, es cierto que "los términos de esos acuerdos deberán ser aprobados previamente por la junta de acreedores respectiva" y que "las prestaciones que deriven de ellos beneficiarán a todos los acreedores, a prorrata de sus respectivos créditos, sin distinguirpara ello la clase o categoría de los mismos" (artículo 465 inciso tercero CP.); pero también es efectivo que la circunstancia que un bien jurídico sea de titularidad de un conjunto de acreedores no convierte a dicho interés en un bien jurídico supraindividual. Antes bien, un interés colectivo es, de conformidad con lo indicado supra ${ }^{82}$, aquel que es de titularidad o sirve a la generalidad de las personas que integran el cuerpo social. Tal titularidad difusa se opone a la titularidad que corresponde a personas determinadas (los acreedores del deudor insolvente), por muy numerosas que éstas sean.

A mayor abundamiento, en el Informe de la Comisión de Constitución presentado en la discusión de la Ley N. 20.720 se recoge la opinión del profesor Héctor Hernández Basualto, quien destacó que si se acogía la tesis de que los delitos concursales tutelaban un bien jurídico colectivo, como el orden público económico, no procederían los acuerdos reparatorios ${ }^{83}$. Pues bien, la opción definitiva del legislador fue consagrar la posibilidad de celebrar acuerdos reparatorios respecto de (todos) los delitos concursales tipificados en el CP., lo que permite concluir que se excluyó que éstos protegieran bienes jurídicos supraindividuales como la fe pública, la administración de justicia o el orden público económico.

Se hace hincapié en que se excluiría la tutela de bienes jurídicos su-

${ }^{81}$ Acuerdos cuya aprobación, según el inciso final del artículo 241 CPP., puede ser negada por el juez de garantía, "si existiere un interés público prevalente en la continuación de la persecución penal", entendiéndose que concurre especialmente este interés "si el imputado bubiere incurrido reiteradamente en hechos como los que se investigaren en el caso particular". Sobre este punto y el sentido del término "bien jurídico disponible de carácter patrimonial” véase Duce, Mauricio - Riego, Cristián, Proceso Penal (Santiago, Editorial Jurídica de Chile, 2007), pp. 340 y ss.

${ }^{82}$ Véase el punto I.

${ }^{83}$ Historia de la Ley $\mathrm{N}^{\circ} 20.720$, p. 1376 (disponible en: www.bcn.cl). 
praindividuales como la fe pública, la administración de justicia o el orden público económico, ya que el ordenamiento jurídico chileno permite la celebración de acuerdos reparatorios a propósito de los delitos tributarios y aduaneros, o sea, en relación con figuras delictivas que protegen un bien jurídico supraindividual, como es el patrimonio estatal. Con todo, la posibilidad de que se verifique uno de dichos acuerdos respecto de esos delitos parece estar directamente vinculada con el carácter patrimonial del objeto de tutela de tales ilícitos. Desde este punto de vista, se trataría de una norma excepcional, que no pretende establecer como regla la procedencia de acuerdos reparatorios a propósito de todos los delitos que afectan bienes jurídicos supraindividuales, sino que sólo en relación con algunos, en razón del sentido patrimonial del bien jurídico protegido. Y ya que los delitos concursales no tutelan el patrimonio del Estado, tampoco puede afirmarse que integren, junto con los delitos tributarios y aduaneros, aquel grupo de ilícitos que, protegiendo intereses de carácter supraindividual (patrimonial), admiten excepcionalmente la celebración de esa clase de acuerdos.

3. Formas que asume la afectación de los intereses patrimoniales de los acreedores producto de la comisión de delitos concursales

Desde el punto de vista de la forma concreta que asume la afectación del bien jurídico tutelado, los delitos concursales constituyen figuras de lesión de los intereses patrimoniales de los acreedores de la empresa deudora.

En efecto, tanto los comportamientos que puede cometer el deudor, de los artículos 463 y 463 bis CP. (delito de provocación o agravación de la insolvencia, delito de ocultamiento de bienes o haberes, delito de distracción o de disposición de bienes) como las conductas que puede llevar a cabo el veedor o liquidador, de los artículos 464 número 1 y 464 bis CP. (delito de apropiación o de distracción de bienes), que se dirigen contra los bienes de la empresa deudora, suponen un menoscabo de las posibilidades de los acreedores de perseguir sus créditos en el patrimonio del deudor -y no un mero riesgo o peligro de que el pago no se verifique-, menoscabo que se expresa ya sea en la imposibilidad o en la grave dificultad de demandar y lograr dicho pago. Lo mismo cabe decir de las conductas que puede cometer el veedor o liquidador, del artículo 464 números 2 y 3 CP. (delito de defraudación o de proporción de ventajas indebidas), cuya víctima constituye, por expresa disposición legal, uno o más acreedores de la empresa deudora. Ello por lo demás es coherente con la vinculación que existe entre el concepto genérico de insolvencia, por una parte, y la noción de defraudación o fraude, por la otra, de acuerdo con lo indicado 
supra $^{84}$. En ese orden de ideas, las conductas delictivas que suponen una defraudación o fraude constituyen comportamientos de lesión de los intereses patrimoniales de otro y no de simple riesgo o peligro de afectación de tales intereses.

De otro lado, a idéntica conclusión puede llegarse respecto de las conductas tipificadas en el artículo 463 ter CP. (delito relativo a la situación financiera y delito relativo a la situación contable del deudor). En ese sentido, si bien podría llegar a establecerse cuál es el activo y el pasivo de la empresa deudora a través de medios diversos de los antecedentes o de la contabilidad que el deudor debe proporcionar, su entrega en términos deficientes puede dificultar considerablemente las probabilidades de que los acreedores estén en condiciones de demandar y lograr el pago de sus respectivos créditos. Consiguientemente, también en este caso estamos ante comportamientos que suponen un menoscabo de las posibilidades de los acreedores de perseguir sus créditos en el patrimonio del deudor -y no un mero riesgo o peligro de que el pago no se verifique-, menoscabo que se expresa ya sea en la imposibilidad o en la grave dificultad de demandar y lograr dicho pago. Con todo, debe reconocerse que en este caso la lesión del bien jurídico normalmente será menos intensa que aquella que tendrá lugar cuando el comportamiento recaiga directamente sobre los bienes de la empresa deudora. Tal diferencia en cuanto a la intensidad de la lesión del bien jurídico se ve reflejada en la penalidad aplicable, que es más alta respecto de los delitos de los artículos 463 y 463 bis que de las figuras del artículo 463 ter CP.

Dicho planteamiento se ve reforzado si se parte de la base de que también los tipos de alzamiento de bienes y de otorgamiento de contratos simulados en perjuicio de los acreedores del artículo 466 CP. están configurados como delitos de lesión, y no de peligro. En efecto, ambos tipos penales exigen actuar en perjuicio de los acreedores, exigencia que debe ser interpretada como un elemento del tipo -concretamente como un perjuicio típico- y no como un elemento subjetivo distinto del dolo. Ello se basa fundamentalmente en dos consideraciones. La primera es que los aludidos delitos, de acuerdo con la denominación del Párrafo $7^{\circ}$ del Título IX del Libro II CP., constituyen defraudaciones ${ }^{85}$, y las defrauda-

${ }^{84}$ Véase el punto I.

85 Ello puede sostenerse, históricamente, desde la dictación del CP., que denominaba al Párrafo $7^{\circ}$ del Título IX del Libro II De las defraudaciones; pero también ahora, producto de las modificaciones introducidas por la Ley N. ${ }^{\circ} 20.720$, que pasó a llamar a dicho Párrafo De los delitos concursales y de las defraudaciones. $\mathrm{Y}$ siendo los delitos concursales aquellos que se regulan entre el artículo 463 y el artículo 465 bis, las defraudaciones, por fuerza, tienen que ser las consagradas en el artículo $466 \mathrm{CP}$. 
ciones son figuras que importan, en algún sentido, la provocación de un perjuicio patrimonial ajeno a través de determinados medios. La segunda es que el tipo de alzamiento de bienes exige que el deudor se alce con sus bienes en perjuicio de sus acreedores o que se constituya en insolvencia por ocultación, dilapidación o enajenación maliciosa de esos bienes. Pues bien, cuando se dice que el deudor ha de constituirse en insolvencia, no se está exigiendo que genere un peligro de dicho estado patrimonial crítico, sino que lo provoque efectivamente. La redacción de tal requisito es idéntica a la del perjuicio que, en ese orden de consideraciones, también ha de ser efectivo y no meramente potencial. Siendo el alzamiento de bienes y el otorgamiento de contratos simulados en perjuicio de los acreedores figuras de lesión, lo mismo cabe decir de los delitos concursales que, desde el punto de vista de la ofensividad del comportamiento, se ubican un paso más allá que las figuras delictivas del artículo $466 \mathrm{CP}$.

\section{BIBLIOGRAFÍA}

Antolisei, Francesco, Delitos relacionados con las quiebras y las sociedades (traducción de Francisco Bruno y Jorge Guerrero, Bogotá, Editorial Temis, 1964).

Bawlitza, Cristián, Delitos concursales, en Balmaceda, Gustavo, Manual de Derecho Penal, Parte Especial (Santiago, Librotecnia, 2014).

Bustos, Juan, Política criminal y bien jurídico en el delito de quiebra, en Anuario de derecho penaly ciencias penales, 43 (1990).

Caballero, Felipe, Insolvencias punibles (Madrid, Iustel, 2008).

CAEIRO, Pedro, Sobre a natureza dos crimes falenciais (o património, a falência, a sua incriminação e a reforma dela) (Coimbra, Coimbra Editora, 1996).

Carrara, Francesco, Programa de Derecho Criminal, Parte Especial (traducción de José Ortega y Jorge Guerrero, Bogotá, Editorial Temis, 1964), VII.

Cervini, Raúl, Aproximación conceptual integrada al derecho penal económico, en RUBINSKA, Ramiro M. - Schurjin Almenar, Daniel (coordinadores), Derecho penal económico (Buenos Aires, Marcial Pons, 2010), I.

Contador, Nelson - Palacios, Cristián, Procedimientos concursales (Santiago, Thomson Reuters, 2015).

Contreras, Osvaldo, Instituciones de Derecho Comercial (3. a edición actualizada, Santiago, Legal Publishing, 2011), II.

Corcoy, Mirentxu, Delitos de peligro y protección de bienes jurídicopenales supraindividuales (Valencia, Tirant lo Blanch, 1999).

Dannecker, Gerhard - Knierim, Thomas - Hagemeier, Andrea, Insolvenæstrafrecht ( $2^{a}$ edición revisada, Heidelberg, C. F. Müller, 2012).

Duce, Mauricio - Riego, Cristián, Proceso Penal (Santiago, Editorial Jurídica de Chile, 2007).

Erbetta, Daniel, Delitos de insolvencia (Buenos Aires, Hammurabi, 2009).

Etcheberry, Alfredo, Derecho Penal, Parte Especial (reimpresión de la 3. ${ }^{a}$ edición revisada y actualizada, Santiago, Editorial Jurídica de Chile, 2010), III. 
Feijoo SÁnchez, Bernardo, Cuestiones actuales de Derecho Penal Económico (Montevideo - Buenos Aires, B de f, 2009).

Fernández, Gonzalo, Bien jurídico y sistema del delito (Montevideo - Buenos Aires, B de f, 2004).

Ferrajoli, Luigi, El principio de lesividad como garantía penal (traducción de Diana Restrepo Rodríguez), en Revista de Derecho Penal y Criminología, 8 (2012).

Frister, Helmut, Strafrecht Allgemeiner Teil (7. a edición, München, Beck, 2015).

Garrido Montt, Mario, Derecho Penal, Parte Especial (reimpresión de la 4. ${ }^{a}$ edición, Santiago, Editorial Jurídica de Chile, 2011), IV.

González Cussac, José Luis, Lección XXV, Delitos contra el patrimonio y el orden socioeconómico (VIII): frustración de la ejecución e insolvencias punibles, en GONZÁLEZ CuSSAC, José Luis (coordinador), Derecho Penal, Parte Especial (4. ${ }^{a}$ edición actualizada a la ley orgánica 1/2015, Valencia, Tirant lo Blanch, 2015).

Hassemer, Winfried, Darf es Straftaten geben, die ein strafrechtliches Rechtsgut nicht in Mitleidenschaft ziehen?, en HeFENDEHL, Roland - vON HiRsch, Andrew - Wohlers, Wolfgang (editores), Die Rechtsgutstheorie (BadenBaden, Nomos, 2003).

HefendeHL, Roland, Kollektive Rechtsgüter im Strafrecht (Köln, Carl Heymanns Verlag, 2002).

KaHLO, Michael, Über den Zusammenhang von Rechtsgutsbegriff und objektiver Zurechnung im Strafrecht, en Hefendehl, Roland - von Hirsch, Andrew Wohlers, Wolfgang (editores), Die Rechtsgutstheorie (BadenBaden, Nomos, 2003).

KInDHÄUSER, Urs, Gefäbrdung als Straftat (Frankfurt am Main, Vittorio Klostermann, 1989).

Kindhäuser, Urs, Vor $\iiint 283$ bis 283 d, en Kindhäuser, Urs - Neumann, Ulfrid - Paeffgen, Hans-Ullrich, Nomos Kommentar, Strafgesetz̧buch (4. ${ }^{a}$ edición, BadenBaden, Nomos, 2013), III.

Krause, Daniel-Marcus, Ordnungsgemäßes Wirtschaften und Erlaubtes Risiko (Berlin, Duncker \& Humblot, 1995).

Labatut, Gustavo, Derecho Penal (reimpresión de la 7. a edición actualizada por el profesor Julio Zenteno, Santiago, Editorial Jurídica de Chile, 2012), II.

Lascurain, Juan Antonio, Bien jurídico y legitimidad de la intervención penal, en Revista Chilena de Derecho 22 (1995) 2.

Martínez-Buján Pérez, Carlos, Derecho Penal Económico, Parte General (Valencia, Tirant lo Blanch, 1998).

MAYer Lux, Laura, El bien jurídico protegido en los delitos informáticos, en Revista Chilena de Derecho, 44 (2017) 1.

Mayer Lux, Laura - Fernandes Godinho, Inês, La estafa como delito económico, en Revista de Derecho de la Pontificia Universidad Católica de Valparaíso XLI (2013).

Mayer Lux, Laura - Vera Vega, Jaime, Relevancia jurídicopenal de la conducción vebicular sin la correspondiente licencia, en Doctrina y Jurisprudencia Penal, Edición Especial (2014).

Mir Puig, Santiago, Bien jurídico y bien jurídicopenal como límites del Ius puniendi, en Estudios Penales y Criminológicos 14 (1989-1990).

Mir Puig, Santiago - Gallego Soler, José Ignacio, Responsabilidad civil derivada de los delitos de alzamiento, en López Barja DE Quiroga, Jacobo - Zugaldía Espinar, José Miguel (coordinadores), Dogmática y ley penal, Libro Homenaje a Enrique Bacigalupo (Madrid - Barcelona, Marcial Pons, 2004), II.

Monge Fernández, Antonia, El delito concursal punible tras la reforma penal de 2015 (Análisis de los artículos 259 y 259 bis CP) (Valencia, Tirant lo Blanch, 2016). 
Muñoz Conde, Francisco, Derecho Penal, Parte Especial (18 edición revisada y puesta al día, Valencia, Tirant lo Blanch, 2010).

Muñoz Conde, Francisco, Introducción al derecho penal ( $2^{a}$ edición, Montevideo - Buenos Aires, B de f, 2001).

Navarro, Guillermo Rafael - Rizzi, Aníbal Horacio, El delito de quiebra (Buenos Aires, Hammurabi, 2004).

Navas, Iván, Insolvencias punibles: Fundamentos y límites (Madrid, Marcial Pons, 2015).

Oliver, Guillermo, Delitos contra la propiedad (Santiago, Legal Publishing, 2013).

Ortiz, Luis, Delincuencia económica, en Problemas Actuales de Derecho Penal (Temuco, Universidad Católica de Temuco, 2003).

Polaino, Miguel - Polaino-Orts, Miguel, Las insolvencias punibles en la encrucijada del derecho penal y del derecho mercantil: Tras la aprobación de la nueva Ley Concursal española (Bogotá, Universidad Externado de Colombia, Colección de Estudios N. 32, 2005).

Politoff, Sergio - Matus, Jean Pierre - Ramírez, María Cecilia, Lecciones de Derecho Penal Chileno, Parte Especial (reimpresión de la 2. ${ }^{a}$ edición, Santiago, Editorial Jurídica de Chile, 2011).

Puga, Juan Esteban, Derecho Concursal, Del procedimiento concursal de liquidación, Ley $N^{\circ}$ 20.720 (reimpresión de la 4. ${ }^{a}$ edición actualizada, Santiago, Editorial Jurídica de Chile, 2015).

Queralt, Joan, Derecho Penal Español, Parte Especial (7. a edición revisada y actualizada, Valencia, Tirant lo Blanch, 2015).

Rodríguez Collao, Luis - Ossandón Widow, Magdalena, Delitos aduaneros (Santiago, Editorial Jurídica de Chile, 2010).

Rodríguez Collao, Luis - Ossandón Widow, Magdalena, Delitos contra la función pública (reimpresión de la 2. edición actualizada, Santiago, Editorial Jurídica de Chile, 2011).

Romano, Mario, Zur Legitimation der Strafgesetze. Zu Fäbigkeit und Grenzen der Rechtsgutstheorie, en Heinrich, Manfred - Jäger, Christian - Schünemann, Bernd (editores), Strafrecht als Scientia Universalis, Festschrift für Claus Roxin zum 80. Geburtstag am 15. Mai 2011 (Berlin - New York, De Gruyter, 2011), I.

RudolPhi, HansJoachim - Jäger, Christian, Vor $\int 1$, en Wolter, Jürgen (editor), Systematischer Kommentar zum Strafgesetz̧buch, $\$ \int 145$ b StGB (8. ${ }^{a}$ edición, Köln, Carl Heymanns Verlag, 2014), I.

Sandoval, Ricardo, Reorganización y liquidación de empresas y personas. Derecho concursal (reimpresión de la 7. a edición, Santiago, Editorial Jurídica de Chile, 2015).

Souto García, Eva María, Frustración de la ejecución e insolvencias punibles (Arts. 257 y ss.), en González Cussac, José Luis (director), Comentarios a la Reforma del Código Penal de 2015 (2. ${ }^{a}$ edición, Valencia, Tirant lo Blanch, 2015).

SternbergLieben, Detlev, Rechtsgut, Verhältnismäßigkeit und die Freiheit des Strafgesetzggebers, en Hefendehl, Roland - von Hirsch, Andrew - Wohlers, Wolfgang (editores), Die Rechtsgutstheorie (BadenBaden, Nomos, 2003).

Tiedemann, Klaus, El concepto de derecho económico, de derecho penal económico y de delito económico, en Revista Chilena de Derecho, 10 (1983).

Tiedemann, Klaus, Wirtschaftsstrafrecht Besonderer Teil ( $3^{\text {a }}$ edición actualizada y ampliada, München, Vahlen, 2011). 
VARgas PINTo, Tatiana, Nuevo régimen punitivo concursaly sus principales desafíos, en JEQUIER LeHuedé, Eduardo (editor), Estudios de Derecho Concursal, La Ley No 20.720, a un año de su vigencia (Santiago, Thomson Reuters, 2016).

Vargas Sielfeld, Nadín, Los delitos concursales del deudor (memoria inédita, Pontificia Universidad Católica de Valparaíso, Valparaíso, 2015). 